\author{
Pablo Garcés Velástegui \\ Instituto de Altos Estudios Nacionales, Ecuador \\ Pontificia Universidad Católica del Ecuador \\ pablo.garces@iaen.edu.ec
}

\begin{abstract}
Development policy, like all public policy, is based on a strong notion of causality. Interventions take place in the expectation they will produce development. Two elements are relevant. First, given the variety of contexts and people where these interventions take place, it is of the greatest importance to study assumptions regarding the causal mechanisms that lead to certain outcomes since these are largely determined by the assumptions. Second, the very concept of development that influences public policy warrants discussion, since it is not only a descriptive notion but also a normative one. In a bid to contribute to the design and analysis of public policy, both elements are, therefore, addressed in this article. In the case of causality, it argues in favor of multiple causality and suggests that it should be addressed using fuzzy-set qualitative comparative analysis (fsQCA). As regards the concept of development, it advocates a focus on people and proposes the human development and capability approach.
\end{abstract}

Keywords: Fuzzy sets, Qualitative comparative analysis, Multiple causality, Capabilities, Development policy. 


\section{DIVERSAS CAUSAS, SIMILARES RESULTADOS: REEVALUANDO LOS MEDIOS Y FINES DE LA POLÍTICA DE DESARROLLO EMPLEANDO CAUSALIDAD MÚLTIPLE Y CAPACIDADES}

\section{RESUMEN}

La política de desarrollo, como toda política pública, está basada en una fuerte noción de causalidad. Las intervenciones son implementadas con la expectativa de que producirán 'desarrollo'. Dos elementos resultan relevantes. En primer lugar, dada la variedad de contextos y personas involucrados en estas intervenciones, es importante estudiar los supuestos asociados a los mecanismos causales que llevan a ciertos resultados, ya que, precisamente estos resultados dependen de los supuestos. En segundo lugar, el concepto de desarrollo que influye en la política pública debe ser discutido, pues no es solo una noción descriptiva sino también normativa. Por lo tanto, ambos elementos son analizados en este artículo, con el fin de contribuir a la formulación y análisis de la política pública. Con respecto a la causalidad, se argumenta a favor de la causalidad múltiple y se propone estudiarla a partir del uso del análisis cualitativo comparado con conjuntos difusos. Respecto al concepto de desarrollo, se argumenta a favor de un acercamiento enfocado en la gente. Para ello, se propone el enfoque de desarrollo humano y de las capacidades.

Palabras clave: Conjuntos difusos, Análisis cualitativo comparado, Causalidad múltiple, Capacidades, Política de desarrollo. 


\section{INTRODUCTION}

Development policy, like virtually all policy, builds rather strongly on a notion of causality. Interventions are implemented to cause certain outcomes. This underscores the importance of knowing what works, when and how; that is, a study of causality. Such scrutiny can only be made after the fact by dint of policy assessment, which consists on analyzing whether a policy met its intended goals (Birkland 2011). The implications of such exercises can be enormous. Depending on the assumptions made, the methods used, the indicators employed, etc. different conclusions can be reached and these will be factored into policy anew. At the same time, those causes are expected to lead to some ends. The latter are desirable states associated with the very notion of development. Depending on the ends pursued and how they are studied, measured and captured, different conclusions may also be reached in policy evaluation. Therefore, it seems warranted to look at how that causality is accounted for and which outcomes are desirable.

Development policy analysis is not an unbiased exercise. "[W]e see the world through lenses not only shaped by our ideologies but also shaped by the statistics we use to measure what is going on, the latter being frequently linked to the former" (Stiglitz, Sen and Fitoussi 2010: xix). Therefore, the methods employed to assess whether or not policies met the intended goals depend, to a great extent, on the preferences of those doing the assessment. By far the conventional approach to policy evaluation has been based on quantitative methods and the statistical template. This strategy can be, and has been, quite useful for the study of causality. However, since it is mostly interested in identifying the single model that best fits the data, it seems to assume that there is one pathway leading to the outcome. As such, it is arguably best suited to study one kind of causality, namely, single causality.

Nevertheless, in development policy there is likely to be various pathways to the same or similar outcome. This is especially the case when dealing with people. Policies often establish minimum cut-off points on an indicator of interest that different people from different contexts are expected to meet. This means that policies arguably entail a notion of multiple causality. When this is the case, a method suited for the study of multiple causality is required in order to study what works, when and how. Fuzzy set qualitative comparative analysis (fsQCA) is a method designed to account for those cases (Ragin 2000, 2008). Hence, in cases where there are good reasons to assume that there may by many causes for the same outcome, fsQCA could prove useful. 
If studying the means to development is warranted, studying the ends is even more so. In development policy, interventions are implemented to achieve, well, development. But what is development? This is a relevant question since the notion of development is not solely a descriptive but a normative one. Development is a value-laden concept. It suggests the idea of improvement, betterment, advancement (Alkire and Deneulin 2010a). Therefore, a discussion about development is a discussion about what is worth improving, bettering, advancing. As Gasper (2008: 239) states "[v]alues, implicit or explicit, necessarily affect choice of focus, including boundaries of analysis in explanation and situation definition in policy analysis". By so doing, it also suggests how to identify it, how to measure it and, in the case of explanatory theories, even how to attain it.

For the most part of the twentieth century the dominant idea of development has been in terms of opulence. Indicators such as Gross Domestic Product (GDP) or Gross National Product (GNP), often per capita, have been used in order to capture the well-being in a country. Development policy, accordingly, has for decades sought to maximize economic growth. However, purchasing power is only valuable to extent that it allows to purchase other valuable things. In that sense, opulence seems to have only instrumental value. In other words, the conventional notion of development, and the policies inspired by it, have sought to pursue only the means to something else.

That 'something else' are the ends themselves of development. In order to study them a different framework than the traditional one is required. The capability approach, arguably the most relevant alternative, seeks to provide such account. It places people at the locus of attention and their quality of life. By so doing it redefines development as the expansion of people's freedoms, considering the latter as those things that have intrinsic value, those things that are valuable in and of themselves.

In this sense, this article is concerned with both the study of the means and the ends of development policy. To do so it is divided into four sections, besides de introduction. The first, introduces fsQCA and argues in favor of employing for the purposes of policy evaluation when there are good reasons to assume multiple causality. The second section argues that there are good reasons to assume so when development policy is evaluated in terms of people's quality of life. Further it argues that development policy outcomes should be evaluated in those terms and, in order to provide a framework that facilitates that endeavor, it advances the capability approach. The third section makes the case for the advantages of using them in tandem for academics and practitioners. The final section 
concludes.

\section{THE MEANS OF DEVELOPMENT POLICY: STUDYING CAUSALITY}

Public policy in general, and development policy in particular is based on a strong sense of causality. Once a phenomenon of public interest is identified as deserving action, interventions are designed and implemented with the expectation that certain outcome is likely to ensue. At best these expectations have been empirically supported consistently, at worst they are based on loose intuitions and high hopes. Nevertheless, the importance of this cannot overstated. From an input- and efficiency-based perspective, scarce resources are invested in policies seeking to attain a given result. From a political perspective, politicians build their platforms and are elected on certain promises which voters expect to be delivered. From an outcome-based perspective, if humans are the ultimate goal of policy, which the second section of this paper argues they are, people's lives may be positively or negatively affected by policies.

In this sense, it becomes necessary to count with the right tools to evaluate policy; that is, to know what works, and under which circumstances. This means placing attention to policy evaluation. If development policy is based on a strong causal notion, it is all the more important to be able to account for that causality adequately. This section is concerned with introducing and elaborating on a method for the study of causation of a specific kind, namely, multiple and conjunctural. The argument seeks to argue in favor of QCA (and fsQCA more specifically) as an additional tool for the policy analyst and policy maker, whenever its use is called for, not for a replacement of previous tools.

\section{QUALITATIVE COMPARATIVE ANALYSIS}

QCA is method dedicated to the analysis of causation of a particular type: multiple. Proposed originally by Charles Ragin's (1987) seminal work, this work has gained increasing attention by academics and practitioners. Although a relatively recent contribution to the literature, it shares the pedigree of John Stuart Mill's work, particularly its method of agreement and method of difference. Regarding the former, Mill (1967: 390) states: "If two or more instances of the phenomenon under investigation have only one circumstance in common, the circumstance in which alone all the instances agree is the cause (or effect) of the given phenomenon". 
Apropos the method of difference, in turn, Mill (1967: 391) asserts:

If an instance in which the phenomenon under investigation occurs, and an instance in which it does not occur, have every circumstance in common save one, that one occurring only in the former; the circumstance in which alone the two instance differ, is the effect, or the causes, or an indispensable part of the cause of the phenomenon.

This approach to causality relies on the comparison of cases so as to identify common causal relationships by eliminating all alternate possibilities. Despite their intuitive logic, Mill's suggestions have proven challenging in applied research. This is because the complexity of phenomena is rarely as straightforward so as to allow such elimination. In their expectation to find a single cause or effect, by controlling all others and the environment, these methods appear rather extreme (Berg-Schlosser et al. 2009). Revising his own work Mill proposed to combine them into what is known as the Joint Method of Agreement and Difference or the Indirect Method of Difference. This consisted on a double application of the Method of Agreement. In Mill's (1967: 396) words:

If two or more instance of which the phenomenon occurs have only one circumstance in common, while two or more instances in which it does not occur have nothing in common save the absence of that circumstance, the circumstance in which alone the two sets of instances differ, is the effect, or the cause, or an indispensable part of the cause, of the phenomenon.

In this sense, Mill's influential contribution has been advancing a systematic process to eliminate irrelevant factors to study causation. These insights have been further enriched by subsequent scholars who have successfully overcome some of its original shortcomings. QCA is an illustration of such efforts.

QCA is a method useful for the study of a particular type of causation: multiple. When there are good reasons to assume that there may be multiple causal paths to the same outcome, as it can often happen in public policy in general $^{1}$.

\section{SET THEORY: AN INTRODUCTION}

In order to employ QCA, concepts need to be converted into sets. This

1 This is particularly so in the case of social policy (see Garcés 2018). 
is what makes it a set-theoretic method. Sets describe groups with clear boundaries composed of items considered in principle homogenous. This means that elements making up a set share one meaningful characteristic justifying their inclusion in the group. For development and social policy, set logic can be useful. A relevant example might be the group of people with disabilities. First, a framework that established what a disability is and how it might be empirically captured (indicators, measurements, etc.) is required. Then from a group of people of interest, the identification of disability is made and a ranking is produced. The result of the exercise is to identify the people who have a disability (according to a certain cutoff point given by theory, face value or another legitimate criterion) and differentiate them from those who do not have a disability.

This simple illustration already shows an important characteristic of set logic. When creating a set, its opposite is created as well. Against common intuition, however, the opposite of 'people with disabilities' is not 'people with abilities' but 'not people with disabilities'. From the same population, therefore, two sets are formed by the translation of concepts into sets. As will become clear in the discussion below, this is a stark contrast with conventional statistical, variable-oriented methods.

Operationalizing social science concepts as sets can be rather useful. The process starts by translating the data into membership scores. At its most basic, the exercise consists on generating what are called crisp sets. This means assigning scores of one (1) and zero (0) (Rihoux and Lobe 2009). The former corresponds to membership and the latter to non-membership of the case within the set. As such, crisp sets capture differences in kind or qualitative distinctions. Returning to the aforementioned example, people identified with a disability will receive the score of (1), and those with no disability receive a score of zero (0). Nevertheless, as the example suggests, disability is not an all or nothing condition. Social sciences concepts rarely, if at al, can fit within a black and non-black view of the world.

Set theory can accommodate the fact that the empirical manifestations of concepts are often a matter of degree. Fuzzy set theory goes one step further than crisp sets and allows for partial membership within a set (Smithson and Verkuilen 2006). "[A] fuzzy set is a continuous set that has been carefully calibrated to indicate degree of membership" (Ragin 2000: 154). As such, it is possible to capture both differences in degree (different quantitative states) and differences in kind (different qualitative states). In this sense, going back to the established example, in addition to membership and non-membership, fuzzy sets allow for the identification and capture of the different magnitudes in which disability can take place. 
As this telling example suggests, the fuzziness is not an empirical defect solvable with increasingly sophisticated measurement techniques in order to turn it into exactness. Rather, the fuzziness lies on the concept itself and the fact that non-clear cut boundaries is an intrinsic characteristic (Schneider and Wagemann 2012).

Table 1: Fuzzy set calibration example

\begin{tabular}{|c|c|c|c|c|}
\hline Crisp set & $\begin{array}{c}\text { Three-value } \\
\text { fuzzy set }\end{array}$ & $\begin{array}{c}\text { Four-value } \\
\text { fuzzy set }\end{array}$ & $\begin{array}{c}\text { Six-value fuzzy } \\
\text { set }\end{array}$ & $\begin{array}{c}\text { "continuous" } \\
\text { fuzzy set }\end{array}$ \\
\hline 1 = fully in & $1=$ fully in & $\begin{array}{l}1 \text { = fully in } \\
0.67 \text { = more } \\
\text { in than out } \\
0.33=\text { more } \\
\text { out than in }\end{array}$ & $\begin{array}{c}1=\text { fully in } \\
0.8=\text { mostly } \\
\text { in but not } \\
\text { fully in } \\
0.6=\text { more or } \\
\text { less in } \\
0.4=\text { more or } \\
\text { less out } \\
\begin{array}{c}\text { but not fully } \\
\text { out }\end{array}\end{array}$ & $\begin{array}{c}1 \text { = fully in } \\
\text { Degree of } \\
\text { membership is } \\
\text { more "in" than } \\
\text { "out": } 0.5<\mathrm{X} \\
<1 \\
0.5=\text { cross-over: } \\
\text { neither in or } \\
\text { out (maximum } \\
\text { ambiguity) } \\
\text { Degree of } \\
\text { membership is } \\
\text { more "out" than } \\
\text { "in": } 0.5<\mathrm{X}<1\end{array}$ \\
\hline $0=$ fully out & $0=$ fully out & 0 = fully out & $0=$ fully out & $0=$ fully out \\
\hline
\end{tabular}

Source: Ragin (2000).

Thus, fuzzy sets take the nature of concepts seriously. This entails important challenges for the researcher. The burden of calibration, the assignment of membership scores to the data, is more demanding than in the case of crisp sets. Contra convention, in which calibration is usually 
based on measurements of central tendency and dispersion (Ragin 2000), fuzzy sets use external standards, often employing face validity (Ragin 2008). This means, establishing legitimate qualitative anchors to specific membership scores (Ragin 2000, 2008).

\section{Cases instead of Variables}

As suggested above, by focusing on cases QCA offers an alternative to the statistical convention, where the focus is on variables. For QCA, cases are regarded as configurations of conditions, which are the variables in traditional quantitative methods. This highlights the attention that the method places on complexity, a feature closely associated with qualitative methods. In this sense, cases are treated as complex configurations of features, infusing complexity to the study of causation. Incorporating this into conventional quantitative methods would be extremely demanding, unless large enough populations are used in order to have sufficient degrees of freedom. This means that small- and medium-N studies can be virtually ruled out of quantitative analysis when the number of conditions (variables) is relatively large. As such, QCA proposes a promising bridge between the quantitative-qualitative divide. Such approach becomes particularly relevant in the case of program evaluations with a limited number of subjects and even more so in the case of pilots, which by definitions cover a restricted number of participants.

More broadly, QCA rejects the assumptions made in variable-oriented research. For instance, QCA rejects the premises regarding populations. Variable-oriented studies, after setting the hypothesis to be tested, they define the widest possible population of relevant observations (Ragin 1987) and once it is defined, it is fixed. A wide population enables more exacting tests (in some cases, any test at all, if few degrees of freedom) and allows the researcher to show the breadth of the argument. This is only possible because such populations are conceived of as homogenous. For QCA, conversely, populations are heterogeneous and can always be changed in light of new information (Berg-Schlosser et al. 2009). By assuming the contrary, variable-oriented approaches leave considerable diversity unaccounted for (Ragin 2000).

This entails a stark contrast with conventional approaches to the study of causality. From probabilistic reasoning, QCA focuses on diversity (Ragin 2000). Permanent causality is rejected, unless there are sufficient reasons to assume it, and instead it proposes context and conjuncture specific causality, when there are good reasons for it. The statistical template focuses on identifying the model of best fit, using "means, correlations, 
and regressions-computed across all cases at the same time-which average out the respective constellations and ignore specific, distinct patterns and 'outliers'” (Berg Scholosser et al. 2009: 9). QCA, in turn, identifies the many causal paths that lead to an outcome. Hence, the researcher ought to establish the adequate number of models (Ragin 1987). This means that all causal pathways identified are regarded as equally relevant regardless of the number of cases that each model explains (Berg-Schlosser et al. 2009).

\section{NeCESSARY AND SUFFICIENT CONDITIONS}

Following Mill's tradition, QCA approaches the study of causality by studying necessity and sufficiency. The purpose is to identify all the conditions that might be relevant for the outcome and by elimination, identify those that actually are. Hence, the focus is on necessity and sufficiency. In this sense, only when a condition is present every single time the outcome occurs, it can be considered as necessary for the latter. In other words, without the condition (or combination thereof) the outcome cannot occur, but the condition may lead to more outcomes than the one of interest. In set theoretic terms, the outcome is a subset of the condition or, conversely, the condition is a superset of the outcome. Similarly, only when an outcome occurs every single time a condition (or combinations thereof) is present, then the latter can be regarded as sufficient for the former. In other words, without the outcome, the condition (or combinations thereof) cannot occur, but the outcome can ensue as the product of other conditions (or combinations thereof). Again, put into set theoretic terms, the condition is a subset of the outcome or the outcome is a superset of the condition.

Further, the complexity of social phenomena may require greater detail regarding its causes. An outcome of interest may be the result of more than one cause or condition, which can ensue in a variety of combinations. In order to account for such specificity, QCA can also explore an insufficient but necessary part of a condition which is itself unnecessary but sufficient for the outcome (INUS causes) as well as a sufficient but unnecessary part of a condition which is insufficient but necessary for the result (SUIN causes) (Schneider and Wagemann 2012).

Hence, as a set theoretic method, QCA can be usefully placed within Schneider and Wagemann's (2012: 6, emphasis in the original) succinct account:

Set theoretic methods are approaches to analyzing social reality in which (a) the data consists of set membership scores; (b) relations 
between social phenomena are modeled in terms of set relations; and (c) the results point to sufficient and necessary conditions and emphasize causal complexity in terms of INUS [and] SUIN causes.

\section{QCA: MAIN CHARACTERISTICS}

QCA is characterized by three features that enable the analysis described above, namely, conjunctural causation, equifinality and asymmetry. I shall describe each briefly in the remainder of this section. Conjunctural causation is closely related to QCA's attention to complexity. Given that cases are composed of combinations of various conditions, set relationships, between causes and outcomes, are expected to be compound. This is a critique of the assumption that variables have a distinct, independent and isolated effect on the outcome, usually made by conventional statistical methods (Berg-Scholsser et al. 2009). For QCA, conditions may only show effects on the outcome in combination. Moreover, the same condition in combination with different conditions may show different (even opposite) effects on the outcome. This is referred to as conjunctutal causation.

Equifinality refers strictly to the possibility that there may be more than one pathway to an outcome, associated with the study of sufficiency as discussed above. Unlike statistical methods, and their pursuit of the one model that best fits the data, QCA assumes that, given good reasons, there can be more than one condition (or combination thereof) leading to an outcome (Schneider and Wagemann 2012). Equifinality conveys the main message of QCA, that multiple causes can bring the same outcome. Added to conjunctutal causation, the result is that QCA is all about: multiple conjunctural causation.

Finally, asymmetry in causality is assumed. This simply means that the presence/absence of an outcome cannot be automatically derived from the presence/absence of a condition (or combination thereof) (Schneider and Wagemann 2012). This is because, as mentioned above, the opposite of one set is its negative, created at the moment the set is created, which may not necessarily correspond to the extremes of the ordering as in conventional variable focused approaches. For example, given a descending distribution of income, those on top are likely to be called rich and those at the bottom poor. However, in order to capture the concepts or 'rich' and 'poor' in sets, two different sets are required, creating four sets in total. The first is the set of 'rich people', the second is its negative byproduct, the set of 'not rich people'. By the same logic, the third and fourth sets are 'poor people' and 'not poor people'. 
These characteristics highlight QCA's focus on diversity. This is a halfway point between complexity (the turf of qualitative methods) and generality (the turf of quantitative methods) (Ragin 2000). This means that it neither regards populations as homogenous and fixed (as in quantitative approaches) nor privileges the specificity of individual cases (as in qualitative studies). In order to operationalize the analysis, what the literature has called a truth table is employed (see Table 2). An explanation of how the analysis goes lies beyond the scope of this paper but suffice it to mention show how the characteristics are displayed in practical terms (for details see Schneider and Wagemann 2012, Ragin, 2000, 2008).

\section{Table 2: Illustration of a truth table}

\begin{tabular}{lrrrrrrrrrrr} 
Cases & \multicolumn{1}{c}{ Conditions } & & & \multicolumn{1}{c}{ Outcome } \\
\hline & A & $\sim$ A & B & $\sim$ B & C & $\sim$ C & D & $\sim$ D & Y & $\sim$ \\
Case 1 & 0.5 & 0.5 & 1 & 0 & 0 & 1 & 1 & 0 & 0.7 & 0.3 \\
Case 2 & 0.7 & 0.3 & 0.3 & 0.7 & 0 & 1 & 1 & 0 & 0.5 & 0.5 \\
Case 3 & 1 & 0 & 0 & 1 & 0.3 & 0.7 & 1 & 0 & 0 & 1 \\
Case 4 & 1 & 0 & 0.7 & 0.3 & 0.1 & 0.9 & 1 & 0 & 1 & 0 \\
Case 5 & 1 & 0 & 0.7 & 0.3 & 0.3 & 0.7 & 1 & 0 & 1 & 0 \\
Case 6 & 1 & 0 & 0.7 & 0.3 & 1 & 0 & 0 & 1 & 0 & 1 \\
Case 7 & 0.5 & 0.5 & 0.5 & 0.5 & 0.3 & 0.7 & 0 & 1 & 0 & 1 \\
Case 8 & 0.3 & 0.7 & 1 & 0 & 0.1 & 0.9 & 0 & 1 & 0.5 & 0.5 \\
Case 9 & 0 & 1 & 1 & 0 & 1 & 0 & 0 & 1 & 0.7 & 0.3 \\
Case 10 & 1 & 0 & 0.3 & 0.7 & 0 & 1 & 0 & 1 & 1 & 0
\end{tabular}

Source: Own elaboration.

The analysis produces a causal models composed of the empirically found combinations of conditions that lead to the outcome of interest. The amount of all possible models depends on the number of conditions as expressed in: $2 \mathrm{k}-1$, where $\mathrm{k}=$ number of conditions. According to the level of parsimony that the exercise may require, Boolean algebra can be used in order to 'minimize' the number of models (Rihoux and Ragin 2006). One need not carry out the exercise by hand, although one could. As the number of cases and conditions grows so too the demands of the exercise. In order to work with increasingly taxing information there is specialized software available at COMPASSS.org, created by a growing community of scholars advancing the use of QCA in many of its variants.

Consequently, fsQCA offers an alternative to the study of causality in which the outcome of interest is seen as the result of multiple cases, i.e. 
various specific combinations of conditions. This is a characteristic feature of social science research, as Mill (1967: 452, emphasis in the original) himself put it,

in politics and history [...] Plurality of Causes exists in almost boundless of excess, and effects are, for the most part, inextricably interwoven with one another. To add to the embarrassment, most of the inquiries in political science relate to the production of effects of a most comprehensive description, such as the public wealth, public security, public morality, and the like: results liable to be affected directly or indirectly either in plus or in minus by nearly every fact which exists, or event which occurs, in human society.

\section{THE ENDS OF DEVELOPMENT POLICY: DISCUSSING DEVELOPMENT}

The causal assumptions in development policy are not the only matter of concern. Perhaps even more important are its expected ends. This is entails a discussion on what development itself is. And development, far from solely a descriptive concept, is a deeply normative one. It conveys the idea of progress, advancement, improvement, etc. These are all valueladen notions and call that which is worth improving or advancing into question. What is more, there may be different ways to attain desired results and some may be more desirable than others. In other words, ideas about development not only point to what is worth bettering but often also suggest how to do so. As such, the results that a policy claims to deliver are relevant in and of themselves.

Where are these ideas about development to be found? They are more conspicuously found in theories of development. The influence of development theories can hardly be overstated. In the international arena, for instance, countries are highly susceptible to what are considered, at a given point in time, relevant development indicators. Global rankings and reports are published every so often exposing how well countries are doing and the latter endeavor to show that they are doing better than others or than they used to (Nussbaum 2011). A telling example is the erstwhile well-established World Development Reports. Unsurprisingly, therefore, a State's development policy aimed at improving its performance in terms of the given indicator so as to show, well, more developed. This conduct is not a thing of the past; countries continue to be influenced by international rankings. Hence, the focus ought to be on the indicators and the idea of development they operationalize. 
Consequently, this section highlights the importance of the ideas about development. To do so, it discusses briefly the dominant approach used and contrasts it with what has increasingly become the main alternative: the capability approach.

\section{THE DOMINANT APPROACH: THE MEANS OF DEVELOPMENT}

For the better part of the twentieth and twenty first centuries the dominant measurement with which to evaluate the state of development of a given country has been economic growth. Whether the per capita of the GDP or GNP (Alkire 2010; Spence 2010), a measure of opulence was the default indicator to assess how well a country was doing. In other words, what has mattered has been how much a country is able to produce in a given period of time. This has been the norm despite the fact that these were intended as an accounting tool, rather than as a unit for the assessment of a country's well-being.

The case in favor using these indicators as measurements of how well a country is doing has meant some sacrifices. One has been the omission of the people. Using growth alone (expressed as GDP or GNP and their variation) has been tantamount to looking at the state as a unitary entity. That is, there is disregard to what goes on within a country. Even when some attention has been given to people, by using per capita indicators, the actual distribution of the wealth of a nation has remained obscured. Further, the situation improves little when using an indicator of opulence closer still to people's actual purchasing power such as income. This is because it has been assumed that using one indicator of opulence can capture other dimensions relevant to people's life (Alkire and Deneulin 2010a).

But measurements of opulence are limited because of other relevant assumptions. In particular, the exclusive use of GDP per capita obscures important aspects of human life such as special needs and happiness (Alkire and Deneulin 2010b; Sen 1999), the composition of growth, activities outside the formal market (Klugman, Rodríguez and Choi 2011), and the effects of the environment (Alkire 2010). Additionally, although the data used by this approach is commonly assumed to be of higher quality than alternatives (Alkire and Deneulin 2010b), the surveys and related instruments on which these measures are based suffer from great deficiencies (Deaton 1997).

There is one logic underlying this practice. It is the the idea that purchasing power is rather coherent with the notion of well-being advanced 
by utilitarianism; that is, that higher income leads to higher consumption and this means higher utility (McGillivray 2007).

Nevertheless, there is increasing evidence that demonstrates that such logic is flowed. If indeed the interest is on people, it is worth acknowledging that countries with high growth levels can have considerable segments of the population suffering great deprivations. In other words, a country may grow and still fail to develop (Ranis, Stewart and Ramirez 2000; Clower, Dalton, Harwitz and Walters 1966).

Indeed, the use of one indicator of opulence entails the assumption that purchasing power either is the only relevant dimension of well-being or comprises the other important dimensions. If it is the latter, the assumption is that, say, income is a good proxy for other aspects relevant to people's lives when in fact they are distinct and there is evidence showing that they are poorly correlated with each other (Nussbaum 2011; Sen 2000). Such assumption opposes the incommensurate character of dimensions relevant to well-being.

This is not to say that pecuniary indicators are useless. To the contrary, they are quite useful for what they can measure: material well-being. This is, of course, only one dimension of well-being. Thus, suggesting that this indicator captures development is analogous to reducing well-being to well-off, thereby equating and mistaking well-being with well-having (Sen 1985). Consequently, monetary indicators have some value but their value is instrumental. That is, they are only valuable to the extent they approximate other intrinsically valuable aspects of people's lives. In other words, by using these indicators development is defined as opulence and this confuses the means with the ends of development.

In practice, the dominance of the pecuniary approach finds its most notable example in the influential World Bank's World Development Reports, which until 1998 ranked countries by per capita income. Reputation and all it entails (e.g. foreign investment, foreign aid, legitimacy etc.) is at stake. Thus, countries strive to improve their positions and implement (development) policies accordingly. The implication is that different policies and consequences will take place depending on the normative assumptions made by the framework and measurement followed (Alkire and Deneulin 2010a). Development policies based on the conventional approach, which take development to mean economic growth, unsurprisingly are likely to generate growth. However, as argued in this section, there are good reasons to question this definition. 
Against this backdrop, an alternative approach seems advised, one that may be able to focus on the ends, rather than the means of development. The capability approach, henceforth CA, placing people and their quality of life at the locus of attention, is arguably that framework.

The capability approach focuses on people and their quality of life. It regards the improvement in people's lives as an extension of their freedom. Therefore, from this perspective, development is about enlarging people's choices in all dimensions of life (Haq 2004). Indeed, Mahbub ul Haq (2004: 31), one of the most relevant contributors to the approach, perhaps put it best:

The human development paradigm covers all aspects of development - whether economic growth or international trade; budget deficits or fiscal policy; savings, investment or technology; basic social services or safety nets for the poor. No aspect of the development model falls outside its scope, but point of references remains the widening of people's choices and the enrichment of their lives. All aspects of life - economic, political or cultural - are viewed from that perspective. Economic growth therefore becomes only a subset of the human development paradigm.

This approach can be usefully understood as asking a couple of questions, namely: i) what are people able to do and be? (Alkire and Deneulin 2010b) and, ii) what have people chosen to do and be? (Robeyns 2017). As will be argued below, these questions highlight some of the most important features of the capability approach. In order to provide an answer for them, the capability approach enlarges the informational space of analysis to cover the dimensions of life that make it worthwhile (Sen 1999). The aim is to include all relevant aspects and, as such, can range from being a house keeper to a professional, to be a member of a church or to be a volunteer, to elect or to be elected, to be educated, to be in good health, to have free time for leisure, to earn the same as others for the same work. In this sense, the rejection of the monetaryonly, one dimensional, single indicator approach is evident. Nevertheless, as mentioned above, the capability approach does not minimize, let alone disregard, the importance that purchasing power has in people's lives. In fact, it recognizes it, but only as one of several other aspects, emphasizing that, unlike them, the value of opulence is solely instrumental (Anand and Sen 1994). This multidimensionality already entails a fundamental challenge to the conventional approach in conceiving the ends of policy: 
The human development paradigm performs an important service in questioning the presumed automatic link between expanding income and expanding human choices. Such link depends on the quality and distribution of economic growth, not only on the quantity of such growth (Haq 1995: 15).

The Human Development paradigm is the product of a several scholars but none has influenced it more than Amartya Sen's capability approach. Hence, an account of the capability approach can be elaborated in terms of the latter. In fact, "[...] there is no consensus as to a conceptually clear distinction between human development and the capability approach, nor is it obvious that such a distinction is useful or required" (Alkire 2010: 22, emphasis in the original). Sen's (1999) framework (re)defines development as freedom. In this sense, it is worth defining it in his own words:

[the capability approach] is an intellectual discipline that gives a central role to the evaluation of a person's achievements and freedoms in terms of his or her actual ability to do the different things a person has reason to value doing or being (Sen 2009: 16).

Going into more detail, three concepts are of special interest for the purposes of this article: capabilities, functionings and conversion factors.

Capabilities are all the valuable doings and beings that people can choose from in order to lead the lives they have reason to value (Sen 1999). As such, they denote the idea of freedom. Contrary to common understandings, this does not entail that the more options, the more freedom a person enjoy. Rather than the quantity, what matters is the quality of the alternatives. Any number of meaningless options cannot compensate for a few highly valued options for people. For instance, a widespread of culinary options in a buffet may mean little if a person cannot find one that suits their belief system (e.g. vegetarian, halal) or health requirements (e.g. lactoseor gluten-free). In this case, all available alternatives, as rich and varied as they may be, would ultimately be meaningless for the individual and his freedom to choose what to eat would be quite constrained. An additional telling example can be that of a young student doing research. The largest library, whether physical or virtual, may mean nothing to the individual if all books and textbooks are written in a foreign language. Even if they were so lucky that the library had exactly the book they were looking for, if it is written in a language unknown by the researcher, this option becomes meaningless. Examples abound and their scope and impact can dramatically increase, but the point remains: capabilities denote the types of life that people have reason to value available to them. 
Functioning, in turn, are the doings and beings that people have reason to value themselves. They are the reasoned valued lives that people live (Sen 1993) making up a person's being (Sen 1990). They are the possible states that an individual may seek to achieve. Examples of doings could be to work for a fair wage, to have access to information, to vote and participate politically, etc. Similarly, examples of beings could be: to be well nourished, to be literate, to be healthy, to be able to appear in public without shame, etc.

Although development can be assessed in both capabilities or functionings. Because Sen (1999) defines development as freedom, he suggests that development should ideally be assessed in the space of capabilities.

The movement from the means to the ends is not, however, unproblematic. In order to translate recourse such as income into capabilities or functionings, it is necessary to take into account the plurality of people there is as well as the diversity of contexts in which they live. Therefore, the ability to turn resources into functionings or capabilities depends on both the feature of the individual and those of their context or environment. These are referred to as conversion factors. They can be internal or external. Internal conversion factors are personal characteristics. External conversion factors are the social, cultural or environmental characteristics surrounding the individual. Both can have a considerable impact on enjoying capabilities or achieving functionings from given resources. One interesting example could be a smart phone. While some may appreciate just the fact of having something that has a price tag, for all (including the latter) it is mostly valuable to the extent that it enables them to communicate with others. However, should a person have a visual (or some other) handicap that disables them to use a conventional apparatus, this personal feature would constraint its ability to communicate with the phone. Likewise, for someone in a rural area without network, a feature of the area where a person may live, the smart phone would be useless as a tool to enhance communication. Similarly, in a society where women are not allowed to establish and nurture social networks among themselves, the presence or absence of a smart phone would make like difference in the achievement of enhanced communication.

Consequently, when it comes to development, the capability approach is a framework that advances moving from the traditional focus on its means to its actual ends. This means placing people and their quality of life at the center of the concept and focusing in those aspects of life that are intrinsically valuable, being important in and of themselves, instead 
of using those only instrumentally important, those that are only valuable to the extent they enable achievements in other intrinsically valuable dimensions. In this sense, the framework follows Aristotle (in Haq 1994: 13) who posited: "wealth is evidently not the good we are seeking, for it is merely useful and for the sake of something else".

The main communicational tools of human development ideas are the Human Development Reports (HDRs), produced by the United Nations Development Program (UNDP). Although the contours of human development have evolved, the core of the concept has remained stable. The first HDR, published in 1990, defined human development as "both the process of widening people's choices and their achieved well-being" (UNDP 1990: 9). Two decades later, in 2010, it was stated "Human Development aims to expand people's freedoms - the worthwhile capabilities people value - and to empower people to engage actively in development processes, on a shared planet. And it seeks to do so in ways that appropriately advance equity, efficiency, sustainability and other key principles." (Alkire 2010: 40). As such, its focus on real freedoms (capabilities), agency and principles of justice is clear. It is also clear that no list of capabilities is prescribed. This is a purposeful feature that evidences the stark contrast with other approaches. It shows the flexibility of the framework to different evaluative exercises as well as its sensitivity to social diversity and change.

These reports serve a twofold purpose. On the one hand, they assess the quality of life of a population (Alkire and Deneulin: 2010b). Each annual report has a particular theme focusing on a subset of capabilities. Additionally, the analysis therein draws on a wealth of data such as health, education, nutrition, inequality, gender, political freedoms, security, and cultural liberties. They, thus, talk across disciplines and political boundaries, much like the CA. On the other hand, they are instruments of advocacy for improvements on that quality of life. They, therefore, constitute a vehicle bringing the pluralistic notion of progress to the assessment of development (Sen 2000) and raising awareness of issues that otherwise would be absent in the political agenda (Alkire and Deneulin 2010b).

Despite the reports' focus on particular themes and related capabilities, three have figured on all issues: "to lead a long and healthy life, to be educated and to enjoy a decent standard of living" (UNDP 1990: 10). They were originally acknowledged as the most critical choices requiring enlargement and have remained a central focus of the reports. Using country level information, they have been operationalized into one composite indicator of development, the Human Development Index. 
The HDRs, being the main vehicle of the approach and its index, have put forward three dimensions considered as basic for human flourishing: health, education and standards of living. As stated above, this seeks to redefine development for policy makers since in order to show improved performance year after year in terms of human development, they have to employ human development enhancing policies. Nevertheless, because of the multidimensional nature of the CA, this list is far from exhaustive. Depending on the exercise and the purpose of the policy, different dimensions and indicators may be of interest.

This means that if, as the World Bank (1999: 13) posits, "[t]he principal goal of development policy is to create sustainable improvements in the quality of life for all people", then development policies should so reflect and, moreover, policy evaluation must contrast a policy's purported aims against its outcomes in those terms. The capability approach offers a framework to facilitate the formulation, implementation and evaluation of such policies.

\section{EMPLOYING THE CAPABILITY APPROACH AND FSQCA TO ASSESS DEVELOPMENT POLICY}

The benefits of the study of multiple causality have not gone unnoticed in policy studies. fsQCA has been increasingly used for policy analysis. In fact, in their quasi-comprehensive of applications of QCA in any of its variants, Rihoux, Rezsöhazy and Bol (2011) found over 150 publications where the method was employed with some relation to policy analysis, although the number concerned with policy evaluation has less than a tenth of the total. Be that as it may, both numbers have only increased in recent years. Nevertheless, in that review of the literature no application had been made thus far in which the cases studied were people. As this section seeks to show, there are many reasons for using fsQCA for policy evaluation placing people at the locus of attention. Moreover, the case in favor of using it together with the capability approach is arguably even more persuasive.

\section{Set theory and the main concepts of the Capability Approach}

"[V]irtually all social science concepts have fuzzy boundaries, and fuzzy sets are a tool for numerically expressing that" (Schneider and Wagemann 2012: 4). Since the capability approach has challenged many established definitions in economics, such as poverty, deprivation, well-being, agency, etc.; and, furthermore, has generated a shared language among various disciplines (Robeyns 2017) this certainly applies to it. In this sense, there 
is a small literature that has timidly argued in favor of using fuzzy sets with the CA. In this sense, Chiappero-Martinetti (2006: 7) has argued that, "[a] chievements are a matter of degree not all or nothing conditions". Indeed, studying doings and beings as if they constitute all or nothing conditions, i.e. full membership or full non-membership, does not seem appropriate since experience itself clearly contradicts it. For instance, people are not either completely healthy or totally sick, they are not either full of selfesteem or void of it. To the contrary, they fall somewhere in between. The dichotomous convention, with its black and non-black conception of the world, cannot account for this empirical fuzziness.

The argument applies to capabilities as well since they are a vector of all possible functionings. The argument is twofold. First, just by aggregation, the more or less functionings available should change the degree to which a capability is enjoyed. Second, there may be different degrees of desirability among possible functionings. There is no reason to assume that all possible types of life that are valued after reflection are equally valued. This means that the inclusion or omission of different alternatives may change the degree to which a capability is enjoyed. One would be hard pressed to identify the point in which a person is completely free and totally non-free. The same applies to the case of converstion factors, internal and external. An example is proposed in Table 3, below. 
Table 3: Illustration of functionings, capabilities and conversion factors as fuzzy sets

\begin{tabular}{cccccccc} 
Functioning & \multicolumn{2}{c}{ Capability } & \multicolumn{2}{c}{$\begin{array}{c}\text { Internal } \\
\text { Factor }\end{array}$} & \multicolumn{2}{c}{$\begin{array}{c}\text { External } \\
\text { Fonversion } \\
\text { Factor }\end{array}$} \\
\hline $\mathrm{A}$ & $\sim \mathrm{A}$ & $\mathrm{B}$ & $\sim \mathrm{B}$ & $\mathrm{C}$ & $\sim \mathrm{C}$ & $\mathrm{D}$ & $\sim \mathrm{D}$ \\
0.2 & 0.8 & 1 & 0 & 0 & 1 & 1 & 0 \\
0.6 & 04 & 1 & 0 & 1 & 0 & 1 & 0 \\
0 & 1 & 0.3 & 0.7 & 0 & 1 & 0.1 & 0.9 \\
1 & 0 & 0.9 & 0.1 & 1 & 0 & 0.1 & 0.9 \\
0.4 & 0.6 & 0 & 1 & 1 & 0 & 0 & 1 \\
0.4 & 0.6 & 0 & 1 & 0 & 1 & 0.3 & 0.7 \\
0.2 & 0.8 & 0.1 & 0.9 & 0 & 0 & 0.7 & 0.3 \\
1 & 0 & 0 & 1 & 0 & 1 & 0.3 & 0.7 \\
0 & 1 & 0.7 & 0.3 & 1 & 0 & 0 & 1 \\
0.2 & 0.8 & 0.7 & 0.3 & 0 & 1 & 1 & 0
\end{tabular}

A Membership in set of people who have access to electricity

- A Membership in set of people who do not have access to electricity

B Membership in set of people who can vote

- B Membership in set of people who cannot vote

C Membership in set of people who are men

- C Membership in set of people who are not men

D Membership in set of people who live in a patriarchic community

- D Membership in set of people who do not live in a patriarchic community

Source: Own elaboration.

All the concepts with which the capability approach is concerned seems to be inherently ambiguous. This means that the boundaries limiting them are fuzzy and, thus, they defy precise establishment. As can be attested from the above, fuzziness in the concepts does not come from measurement but from the concepts themselves. That is, fuzziness or the lack of precision is not a defect of measurement but the nature of the concept. Consequently, no amount of technical sophistication could square that circle and make a fuzzy concept a crisp one, nor would this be desirable. In this light, it 
seems advised to respect, observe and capture that nature. Fuzzy sets are useful to do just that. The importance of taking this approach has been highlighted by Sen (1990: 45):

There are many ambiguities in the conceptual framework of the capability approach. Indeed, the nature of human life and the content of human freedom are themselves far from unproblematic concepts. It is not my purpose to brush these difficult questions under the carpet, in so far as there are genuine ambiguities in the underlying objects of value, these will be reflected in corresponding ambiguities in the characterization of capability. The need for this relates to a methodological point, [...] that if an underlying idea has an essential ambiguity, a precise formulation of that idea must try to capture that ambiguity rather than attempt to lose it. Even when precisely capturing an ambiguity proves to be a difficult exercise, that is not an argument for forgetting the complex nature of the concept and seeking a spuriously narrow exactness. In social investigation and measurement, it is undoubtedly more important to be vaguely right than to be precisely wrong.

\section{INDIVIDUALS REGARDED AS CASES}

Despite the virtues of the CA, or perhaps because of them, applying it to empirical exercises has proven rather difficult (Comim 2008). There is a tension between the high demands of information of the approach and the demands of generalization of policy analysis. While the CA, by focusing on various dimensions and features, requires a lot of information, which make it prone to small $\mathrm{N}$ or micro studies (Comim 2001), policy analysis often requires to be able to study large $\mathrm{N}$ since development policies are often nationwide in scope. This is a challenge that be overcome with the use of QCA since its focus is on diversity, that is, a middle ground between complexity and generalization (Ragin 2000). This does not mean that it is useful only for medium $\mathrm{N}$ studies. In fact, QCA can be usefully utilized for small and large $\mathrm{N}$ studies as well. What it means is that it neither focuses exclusively on internal validity as qualitative studies do nor on external validity as quantitative studies do. Instead, its concern is with both aspects, to a certain extent. Consequently, it enables moderate generalization (Ragin 2008).

Further, QCA's attention to some complexity, manifested in its focus on cases, seems to fit well with insights of the CA. To reiterate, treating observations as cases means regarding them as configurations of many conditions. Through the lens of the capability approach this means that 
humans are regarded as fundamentally complex, made out of a myriad of conditions, which include both personal characteristics as well as those of their surroundings. These conditions are the stuff of which human beings are. Therefore, they are functionings and deprivations, capabilities and unfreedoms, internal and external conversion factors; all of which, can have an effect in meeting (or not) the goals of the policy (see Table 4). 
Table 4: Illustration of people represented as cases using the CA

\begin{tabular}{|c|c|c|c|c|c|c|c|c|c|c|}
\hline Cases & \multicolumn{7}{|c|}{ Conditions } & \multicolumn{3}{|c|}{ Outcome } \\
\hline & A & $-A$ & B & $-B$ & $\mathrm{C}$ & $\sim \mathrm{C}$ & $\mathrm{D}$ & $\tilde{\mathrm{D}}$ & $\mathrm{Y}$ & $-\mathrm{Y}$ \\
\hline Case 1 & 0.5 & 0.5 & 1 & 0 & 0 & 1 & 1 & 0 & 0.7 & 0.3 \\
\hline Case 2 & 0.7 & 0.3 & 0.3 & 0.7 & 0 & 1 & 1 & 0 & 0.5 & 0.5 \\
\hline Case 3 & 1 & 0 & 0 & 1 & 0.3 & 0.7 & 1 & 0 & 0 & 1 \\
\hline Case 4 & 1 & 0 & 0.7 & 0.3 & 0.1 & 0.9 & 1 & 0 & 1 & 0 \\
\hline Case 5 & 1 & 0 & 0.7 & 0.3 & 0.3 & 0.7 & 1 & 0 & 1 & 0 \\
\hline Case 6 & 1 & 0 & 0.7 & 0.3 & 1 & 0 & 0 & 1 & 0 & 1 \\
\hline Case 7 & 0.5 & 0.5 & 0.5 & 0.5 & 0.3 & 0.7 & 0 & 1 & 0 & 1 \\
\hline Case 8 & 0.3 & 0.7 & 1 & 0 & 0.1 & 0.9 & 0 & 1 & 0.5 & 0.5 \\
\hline Case 9 & 0 & 1 & 1 & 0 & 1 & 0 & 0 & 1 & 0.7 & 0.3 \\
\hline \multirow[t]{11}{*}{ Case 10} & 1 & 0 & 0.3 & 0.7 & 0 & 1 & 0 & 1 & 1 & 0 \\
\hline & A & \multicolumn{9}{|c|}{$\begin{array}{c}\text { Membership in set of people who have certain external } \\
\text { conversion factor }\end{array}$} \\
\hline & $-A$ & \multicolumn{9}{|c|}{$\begin{array}{c}\text { Membership in set of people who do not have certain } \\
\text { external conversion factor }\end{array}$} \\
\hline & B & \multicolumn{9}{|c|}{$\begin{array}{c}\text { Membership in set of people who have certain internal } \\
\text { conversion factor }\end{array}$} \\
\hline & $-\mathrm{B}$ & \multicolumn{9}{|c|}{$\begin{array}{c}\text { Membership in set of people who do not have certain } \\
\text { internal conversion factor }\end{array}$} \\
\hline & $\mathrm{C}$ & \multirow{2}{*}{\multicolumn{9}{|c|}{$\begin{array}{c}\text { Membership in set of people who have a given functioning } \\
\text { Membership in set of people who do not have a given } \\
\text { functioning }\end{array}$}} \\
\hline & $-\mathrm{C}$ & & & & & & & & & \\
\hline & $\mathrm{D}$ & \multirow{2}{*}{\multicolumn{9}{|c|}{$\begin{array}{c}\text { Membership in set of people who are the target of a policy } \\
\text { Membership in set of people who are not the target of a } \\
\text { policy }\end{array}$}} \\
\hline & $-\mathrm{D}$ & & & & & & & & & \\
\hline & $\mathrm{Y}$ & \multicolumn{9}{|c|}{$\begin{array}{c}\text { Membership in set of people who present the outcome in } \\
\text { terms of a functioning }\end{array}$} \\
\hline & $-Y$ & \multicolumn{9}{|c|}{$\begin{array}{l}\text { Membership in set of people who do not present the } \\
\text { outcome in terms of a functioning }\end{array}$} \\
\hline
\end{tabular}

Source: Own elaboration. 


\section{Sufficient AND NeCESSARY CONDITIONS AND THE CA}

The focus on sufficiency and necessity is derived from the analysis of set relations. As mentioned above, particularly the attention to sufficiency is what allows to approach causality as a multiple phenomenon. Given that the capability approach argues in favor of recognizing human plurality and context diversity, using a method that may highlight these features not only may contribute to capability inspired empirical research but can also be quite useful for policy evaluation since the outcomes of a policy depend, to a great extent, on both groups of features.

\section{Multiple conjunctural CaUsation and the CA}

As mentioned earlier, multiple conjunctural causation is the type of causation which QCA is concerned. It can helpfully be summarized by describing two of QCA's main characteristics, namely: equifinality and conjunctural causation.

When it comes to conjunctural causation, the resonance with the capability approach is twofold. First, it is important to account for the effect that the presence/absence of some capability/functioning may have in the presence/absence of another. As Sen (1999) suggests, capabilities are interrelated among themselves so that improvements in some are likely to produce improvements in others. This means that betterment in one dimension may not have an isolated, discrete and independent effect from other dimensions. Instead, there may be what could be considered as positive externalities. Put differently, capabilities are not only the ends of development policy but also some of its means. Second, this applies to functionings or lack thereof. Wolff and de-Shalit (2013) have contributed to the literature by introducing what they call fertile functionings and corrosive disadvantages. While the former denotes functionings that are likely to improve others, the latter refers to those deprivations that may have negative effects on other dimensions.

Regarding equifinality, capability approach emphasizes the importance of recognizing the heterogeneity of human experience. Since the approach entails a movement from the means to the ends of development, for policy purposes this means identifying the differences among different people in different contexts that may have an effect in achieving the expected policy results. This may actually be the intuition guiding much development (and social (Garcés 2018)) policy. By establishing minimum goals that in principle all beneficiaries of a policy should meet, being the latter diverse and their environments varied, they are arguably expecting multiple 
causality to take place.

It is the combination of equifinality and conjunctural causation that leads to multiple conjunctural causation. In brief, this is a causality that can analyze phenomena showing that different combinations of conditions may lead to the same or similar outcomes and the the same condition in different combinations may lead to different outcomes. When studying development policy focused on human beings, and there are persuasive reasons to do so as illustrated by the $\mathrm{CA}$, these seem to be rather reasonable assumptions.

\section{CONCLUSION}

Development policy is based on a strong notion of causality. It entails interventions that are expected to deliver certain results. Thus, it becomes relevant to study what are the mechanisms, assumptions and methods used to account for that causality. The conventional method seems to assume that there is one causal model leading to an outcome. This explain why, by far, the dominant approach in policy evaluation has been the use of quantitative methods based on the statistical template. However, policies often establish (minimum) goals that are expected to be met by different subjects under different circumstances. Given this heterogeneity, that expectation seems to suggest that multiple causality is somewhat implicit in development policy. This is particularly so if people are the focus of policy and, as has been argued above, there are good reasons for placing people at the center of development.

In this sense, this article has sought to address both the study of the means as well as the ends of development policy. Regarding the study of the means, it has argued in favor of considering multiple causality as another plausible form of causality. Further, whenever there are good reasons to expect multiple causality occurs, it has suggested that fuzzy set qualitative comparative analysis is a method that can prove useful to account for it.

fsQCA is a set-theoretic method characterized by features that contribute to the study of multiple causality. Regarding the establishment of sets, concepts can be usefully represented as sets. The data collected for each case are calibrated into membership scores establishing thereby both quantitative and qualitatively different states. Apropos cases, they are regarded as configurations of conditions. This is particularly useful when dealing with people as they are treated as complex subjects constituted by configurations of conditions. Concerning set relations, concepts being being subsets or supersets of other are ubiquitous in social science discourse 
(Ragin 2000). Nevertheless, the argument in favor of fsQCA is made as an option that is not necessarily a substitute to more traditional methods but that is complementary to them, depending on what is assumed by the analysis and the purposes of the exercise.

Apropos the ends of development policy, since it is a discussion on what development itself is, the argument has been made in favor of a movement from the focus on instrumentally valuable aspects of life, such as purchasing power, to a focus on intrinsically valuable aspects of life, like freedom. That argument has been made using the capability approach.

Using the capability approach when thinking about prosperity and social progress has another advantage: it will impede policy makers from using mistaken assumptions about human beings in their policies, including how we live together and interact in society and communities, what is valuable in our lives and what kind of governmental and societal support is needed in order for people (and in particular the disadvantaged) to flourish. [...] Understanding people as beings whose nature consists of a plurality of dimensions can help governments to think carefully through all the relevant effects of their policies (Robeyns $2017: 15$ ).

Despite the advantages of the CA, or perhaps because of them, applications in empirical exercises have proven rather daunting. Sen (1999) himself has acknowledged that compromises may have to be made. Presumably, at least to an extent, this acknowledgement answers to the status quo regarding methods, which places quantitative methods as the default approach for empirical exercises. If, however, alternative approaches are considered, perhaps the compromises that such undertaking entails might be considerably reduced.

Compromises are of the utmost importance in policy making. Evidence generated from compromised exercises may be of limited applicability at best and misleading at worst. Hence, reducing those compromises as much as possible is an urgent matter. With that aim in sight, this article has argued, finally, that the combination of fsQCA and capability approach can minimize considerably the compromises made in CA-inspired policy evaluation. This promising synergy has not been acknowledged in the relevant literatures to date and, thus, fleshing it out constitutes the main contribution of this article. By so doing, it could be a useful foundation on which to build empirical exercises, which exceed the scope of this paper, but constitute the next logical step in this research agenda. 


\section{REFERENCES}

Alkire, S. (2010). Human Development: Definitions, Critiques and Related Concepts. Human Development Research Paper 2010/01.

Alkire, S. and Deneulin, S. (2010a). A Normative Framework for Development. In Deneulin, S. and Shahani, L. (Eds), An Introduction to the Human Development and Capability Approach. London: Earthscan.

. (2010b). The Human Development and Capability Approach. In Deneulin, S. and Shahani, L. (Eds), An Introduction to the Human Development and Capability Approach. London: Earthscan.

Anand, S. and Sen, A. (1994). Sustainable Human Development. Unpublished paper written in preparation for the 1994 Human Development Report. New York: United Nations Human Development Report Office.

Berg-Schlosser, D, De Meur, G., Rihoux, B. and Ragin, C. (2009). Qualitative Comparative Analysis (QCA) as an Approach. In Rihoux, B. and Ragin, C. (Eds), Configurational Comparative Methods: Qualitative Comparative Analysis (QCA) and Related Techniques. Thousand Oaks: SAGE Publications.

Birkland. T. (2011). An Introduction to the Policy Process. New York: Routledge.

Chiappero-Martinetti, E. (2006). Capability Approach and Fuzzy Set Theory: description, aggregation and inference issues. In Lemmi, A. and Betti, G. (Eds), Fuzzy Set Approaches to Multidimentional Poverty Measurement. New York: Springer, Economic Studies in Inequality, Social Exclusion and Well-Being.

Clower, R., Dalton, G., Harwitz, M. and Walters, A. (1966). Growth Without Development: An Economic Survey of Liberia. Evanston: Northwestern University Press.

Comim, F. (2001). Operationalizing Sen's Capability Approach. Unpublished paper prepared for the Conference: Justice and Poverty: examining Sen’s Capability Approach. Cambridge.

. (2008). Measuring Capabilities. In Alkire S., Comim F., Qizilibash M, (Eds), The Capability Approach in Human Development: 
Concepts, Applications and Measurement. Cambridge: Cambridge University Press.

Deaton, A. (1997). The Analysis of Household Surveys: A Microeconometric Approach to Development Policy. Washington: The World Bank.

Garcés, P. (2018). Do Many Roads Lead to Rome? Multiple Causation in Monetary Transfers and How to Approach It. Revista de Estudios de Políticas Públicas, 7, 1-11.

Gasper, D. (2008). From 'Hume’s Law' to Problem- and Policy-Analysis for Human Development. Sen after Dewey, Myrdal, Streeten, Stretton and Haq. Review of Political Economy, 20 (2), 233-256.

Haq, M. (1995). Reflections on Human Development. New York: Oxford University Press.

. (2004). The Human Development Paradigm. In FukudaParr, S. and Kumar, S. (Eds.), Readings in Human Development. New York: Oxford University Press.

Klugman, J., Rodríguez, F. and Choi, H. J. (2011). The HDI 2010: New Controversies, Old Critiques. Journal of Economic Inequality, 9 (2), 249-288.

McGillivray, M. (2007). Human Well-being: Issues, Concepts and Measures. In McGillivray, M. (Ed), Human Well-being: Concept and Measurement. New York: Palgrave Macmillan.

Mill, J. S. (1967). A System of Logic: Ratiocinative and Inductive. Toronto: University of Toronto Press.

Nussbaum, M. (2011). Creating Capabilities: The Human Development Approach. Cambridge: Belknap Harvard University Press.

Ragin, C. (1987). The Comparative Method: Moving Beyond Qualitative and Quantitative Strategies. Oakland University of California Press.

Chicago Press. . (2000). Fuzzy-Set Social Science. London: University of 
. (2004). Between Complexity and Parsimony: Limited Diversity, Counterfactual Cases, and Comparative Analysis. Los Angeles: Theory and Research in Comparative Social Analysis, Department of Sociology, UCLA.

of Chicago Press.

. (2008). Redesigning Social Inquiry. Chicago: University

Ranis, G., Stewart, F., and Ramirez, A. (2000). Economic Growth and Human Development. World Development, 25 (2), 197-209.

Rihoux, B., Rezsöhazy, I., and Bol, D. (2011). Qualitative Comparative Analysis (QCA) in Public Policy Analysis: An Extensive Review. German Policy Studies, 7 (3), 9-82.

Rihoux, B. and Lobe, B. (2009). The Case for Qualitative Comparative Analysis (QCA): Adding Leverage for Thick Cross-Case Comparison. In Byrne D. and C. Ragin (Eds), The SAGE Handbook of Case-Based Methods. Thousand Oaks: SAGE Publications.

Rihoux, B. and Ragin, C. (2006). Introduction. In Rihoux, B. and C. Ragin (Eds), Configurational Comparative Methods: Qualitative Comparative Analysis (QCA) and Related Techniques. Thousand Oaks: SAGE Publications.

Robeyns, I. (2017). Well-being, Freedom and Social Justice. Cambridge: Open Book Publishers.

Schneider, C and Wagemann, C. (2012). Set-Theoretic Methods for the Social Sciences: A Guide to Qualitative Comparative Analysis. Cambridge: Cambridge University Press

Sen, A. (1985). Commodities and Capabilities. Cambridge: Cambridge University Press.

. (1990). Development as Capability Expansion. In Griffin, K. and Knight, J. (Eds.), Human Development and the International Development Strategy for the 1990s. London: Macmillan.

. (1993). Capability and Well-being. In Nussbaum, M. and Sen, A. (Eds.), The Quality of Life. Oxford: Clarendon Press. 
University Press.

(1999). Development as Freedom. New York: Oxford . (2000). A Decade of Human Development. Journal of Human Development, 1 (1), 17-23.

. (2009). Capability: Reach and Limit. In ChiapperoMartinetti, E. (Ed.), Debating Global Society: Reach and Limits of the Capability Approach. Milan: Fondazione Giangiacomo Feltrinelli.

Smithson, M. and Verkuilen, J. (2006). Fuzzy Set Theory: Applications in the Social Sciences. London: SAGE Publications.

Spence, R. (2010). Economic Growth. In Deneulin, S. and Shahani, L. (Eds), An Introduction to the Human Development and Capability Approach . London: Earthscan.

Stiglitz, J., Sen, A. and Fitoussi, J. P. (2010). Mis-measuring Our Lives, Why GDP Doesn't Add Up. The Report by the Commission on the Measurement of Economic Performance and Social Progress. London: The New Press.

United Nations Development Program (UNDP). (1990). Human Development Report 1990: Concept and Measurement of Human Development. New York: Oxford University Press.

Wolff, J. and de-Shalit, A. (2013). Disadvantage. London: Oxford University Press.

World Bank. (1999). Entering the 21st Century: World Development Report 1999/2000. New York: Oxford University Press.

Recibido: 25-02-2018

Aceptación de la versión final: 14-12-2018 